\title{
Expression, Localization, and Function of the Nucleolar Protein BOP1 in Prostate Cancer Progression
}

\author{
Jordan E. Vellky, ${ }^{\star \dagger \ddagger}$ Emily A. Ricke, ${ }^{\star \S}$ Wei Huang, ${ }^{\S \oplus}$ and William A. Ricke ${ }^{\star \ddagger \S}$
}

\begin{abstract}
From the Department of Urology, * the Carbone Cancer Center, ${ }^{\ddagger}$ the George M. O’Brien Research Center of Excellence, ${ }^{\S}$ and the Department of Pathology and Laboratory Medicine, "University of Wisconsin School of Medicine and Public Health; and the Cancer Biology Graduate Program, ${ }^{\dagger}$ Department of Oncology, University of Wisconsin-Madison, Madison, Wisconsin
\end{abstract}

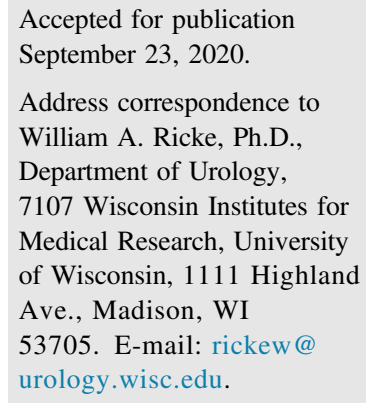

\begin{abstract}
Differentiating between indolent and aggressive prostate cancers (CaP) is important to decrease overtreatment and increase survival for men with the aggressive disease. Nucleolar prominence is a histologic hallmark of CaP; however, the expression, localization, and functional significance of specific nucleolar proteins have not been investigated thoroughly. The nucleolar protein block of proliferation 1 (BOP1) is associated with multiple cancers but has not been implicated in CaP thus far. Meta-analysis of publicly available data showed increased B0P1 expression in metastatic CaP and recurrent CaP, and was inversely associated with overall survival. Multiplexed immunohistochemistry was used to analyze expression and localization of BOP1 and nucleolar protein 56 in human tissue samples from various stages of CaP progression. Here, increased BOP1 expression was observed at later stages of CaP progression, coinciding with a localization change from nuclear to cytoplasmic. In patient samples, cytoplasmic BOP1 was also inversely associated with overall survival. In models of prostate cancer progression, BOP1 expression showed expression and localization similar to that in human patient samples. The functional significance of BOP1 in metastatic CaP was assessed by genetic knockdown, where BOP1 knockdown resulted in decreased proliferation and motility compared with control. Taken together, these data suggest prognostic significance of BOP1 expression and localization in CaP progression and provide a foundation for further investigation into the functional role of nucleolar proteins in advanced CaP. (Am J Pathol 2021, 191: 168-179; https://doi.org/10.1016/j.ajpath.2020.09.010)
\end{abstract}

Prostate cancer $(\mathrm{CaP})$ is a widespread disease with approximately $12.1 \%$ of men in the United States diagnosed with $\mathrm{CaP}$ at some point during their lifetime, according to the Surveillance, Epidemiology, and End Results Program. ${ }^{1,2}$ Fortunately, accessible screening for $\mathrm{CaP}$ has led to a high 5-year survival rate of $97.8 \%{ }^{1,2}$ However, when CaP diagnoses are stratified by stage, the 5-year survival rate for men with localized and regional $\mathrm{CaP}$ is $100 \%$, whereas the 5-year survival rate decreases to only $30.2 \%$ for metastatic prostate cancer. $^{1,2}$ Because of this wide range of $\mathrm{CaP}$ prognoses, many cases of indolent (localized) $\mathrm{CaP}$ are overtreated clinically, whereas aggressive $\mathrm{CaPs}$ that will metastasize are not identified, resulting in undertreatment and/or disease recurrence and decreased survival. ${ }^{3-8}$ This dichotomy between survival among $\mathrm{CaP}$ stages shows a need for biomarkers that can differentiate indolent versus aggressive $\mathrm{CaP}$ to better inform treatment strategies, decrease the financial and psychologic burden of overtreatment, and improve survival rates for metastatic/recurrent $\mathrm{CaP}$.

Histologically, cellular changes in $\mathrm{CaP}$ progression can inform the severity of disease. One such hallmark of $\mathrm{CaP}$ is the development of prominent nucleoli, which has been shown to occur in $\mathrm{CaP}$ stages as early as high-grade intraepithelial neoplasia, and persist through later stages,

Supported by NIH grants U54 DK104310 (W.A.R.), R01 ES001332 (W.A.R.), P30 CA014520 (University of Wisconsin Carbone Cancer Center), and T32 CA009135 (J.E.V.).

Disclosures: None declared. 
including metastasis. ${ }^{9,10}$ In one study, nucleolar size was measured in localized versus metastatic $\mathrm{CaP}$, and indicated a significantly increased nucleolar surface area in metastatic $\mathrm{CaP}$ versus localized $\mathrm{CaP} .{ }^{10}$ Because the nucleolus is the site of ribosomal biogenesis, prominent nucleoli have been associated with several cellular functions including cell-cycle progression and increased proliferation. ${ }^{11-14}$ Although a multitude of proteins and RNAs have been identified within these nucleolar complexes, ${ }^{15}$ expression/ localization changes of specific nucleolar proteins in the progression of $\mathrm{CaP}$ have not been studied as potential biomarkers.

Block of proliferation 1 (BOP1) may be a potential biomarker for indolent versus aggressive $\mathrm{CaP}$. As a component of the pescadillo ribosomal biogenesis factor 1 (PES1)/BOP1/WD Repeat Domain 12 (PeBoW) complex, BOP1 is required for the maturation of the $28 \mathrm{~S}$ and $5.8 \mathrm{~S}$ ribosomal RNAs (rRNA), with processing of these rRNAs resulting in the formation of the $60 \mathrm{~S}$ ribosomal subunit. ${ }^{16,17}$ Functionally, BOP1 is involved in several stages of rRNA processing, and its inactivation in mice results in decreased synthesis of the 60S ribosomal subunit and subsequent cellcycle arrest. ${ }^{12,18}$ BOP1 also has been implicated in several cancer types including colorectal carcinoma, hepatocellular carcinoma, and melanoma. ${ }^{19-21}$ Consistent with its role in cell-cycle progression, BOP1 overexpression in colorectal cancer results in increased multipolar spindles and chromosomal instability. ${ }^{19}$ Interestingly, the role of BOP1 in hepatocellular carcinoma is not limited to its functions in ribosomal biogenesis; in this context, BOP1 promotes invasion and motility, and induces epithelial-to-mesenchymal transition. ${ }^{20}$ Recently, BOP1 also was implicated in a therapy-resistance mechanism in melanoma, suggesting its function may change at later stages of disease progression. ${ }^{21}$ Importantly, despite well-established nucleolar histologic changes associated with prostatic disease, BOP1 expression, localization, and function in $\mathrm{CaP}$ progression is not known.

\section{Materials and Methods}

\section{Meta-Analysis}

Oncomine was accessed online (https://www.oncomine.org, last accessed June 14, 2020) and data sets were analyzed for prostate cancer using cancer versus normal analysis for BOP1. ${ }^{22}$ cBioPortal was accessed online (https://www. cbioportal.org, last accessed June 6, 2020), with data sets analyzed for prostate cancer by filtering for copy number alterations and $B O P 1 .{ }^{23,24}$ Gene Expression Omnibus (GEO) data sets (https://www.ncbi.nlm.nih.gov/geo, accession numbers GSE6919, public on January 30, 2007, ${ }^{25}$ GSE25136, public on November 5, 2010, ${ }^{26}$ and GSE16560, public on March 5, 2010) ${ }^{27}$ were analyzed with the GEO2R analysis tool for BOPI (ID: 35615_at, 212563_at, and DAP4_5968, respectively).

\section{Patient Samples}

The prostate cancer progression tissue microarray (TMA) was generated by a board-certified pathologist (W.H.) and contains approximately 340 cores from approximately 170 patients (2 cores/patient). Histologically determined disease stage was used to stratify patients, resulting in 120 cores (60 patients) of benign tissue, 44 cores (22 patients) of high-grade prostatic intraepithelial neoplasia, 130 cores (65 patients) of $\mathrm{CaP}$, and 32 cores (16 patients) of metastatic tissue (mets). ${ }^{28}$ Diagnosis of cores was confirmed by a pathologist (W.H.) at 10-section intervals. Cores that contained more than 5\% intermixed glands, fewer than 100 total cells, or were damaged significantly during processing were excluded from the analysis. The outcomes TMA contains duplicate $\mathrm{CaP}$ cores with associated clinical data, including survival. ${ }^{28}$ Stratification by survival time (in years) resulted in the following sample sizes: $8+$ years, $n=35 ; 7$ to 8 years, $n=23$; 6 to 7 years, $n=44$; and fewer than 6 years, $n=81$. Both TMAs were constructed in a single institution over the years 1998 to 2006, and the age range for specimens on the TMAs were 37 to 86 years.

\section{Multiplexed Immunohistochemistry and Analysis}

Multiplexed immunohistochemistry was performed using commercially available antibodies against BOP1 (A302149A, 1:125 dilution; Bethyl Laboratories, Inc., Montgomery, TX), nucleolar protein 56 (NOP56; AMAb91013, 1:125 dilution; Sigma Life Science, St. Louis, MO), and Ecadherin (790-4497, undiluted; Ventana, Oro Valley, AZ). All antibodies used in this study have been validated for immunohistochemistry by the vendor. Quantification was performed as previously described. ${ }^{28,29}$ Briefly, the TMA slides were scanned and imaged at $\times 20$ magnification using the Vectra2 quantitative pathology imaging system. inForm Cell Analysis software version 2.1 (PerkinElmer, Waltham, MA) was used to generate spectral libraries of diaminobenzidine, Renoir Red, Vina Green, and hematoxylin, allowing for optical separation of the four stains. Using the Tissue Finder function of inForm, specimens were segmented digitally by tissue type (stroma, epithelia) and cell compartment (nuclear, cytoplasmic). ${ }^{28}$ The mean OD, measured in intensity per pixel, was calculated for each, and the two cores from the same patient were averaged to generate a single mean OD value for each patient.

\section{Cell Culture}

Standard prostate cell lines prostate epithelial transformed by HPV (RWPE-1), prostate cancer bone metastasis (PC3), and prostate cancer brain metastasis (DU145) were obtained from ATCC (Manassas, VA). Benign Prostatic Hyperplasia cell line 1 (BPH1) was generously provided by Dr. Simon Hayward at NorthShore University Health Systems (Evanston, IL), and lymph node carcinoma for the prostate (LNCaP) cells were obtained from collaborators at the University of 
Wisconsin-Madison. BPH1 to Prostate Cancer (BCaP) cell lines were generated in Dr. William A. Ricke's laboratory (Madison, WI) as described previously. ${ }^{30-32}$ All cell lines were maintained in RPMI1640 + $2.05 \mathrm{mmol} / \mathrm{L}$ L-glutamine media (Hyclone, Chicago, IL) supplemented with 5\% fetal bovine serum (Hyclone), 2.5\% HEPES (Hyclone), 1\% penicillin/ streptomycin (Hyclone), $0.2 \%$ normacin (Invivogen, San Diego, CA), and routinely passaged.

\section{Quantitative PCR}

RNA was isolated using the Maxwell 16 LEV simplyRNA Purification kit (AS1270; Promega, Madison, WI), and cDNA was made using iScript Reverse Transcription Supermix (1708841; BioRad, Hercules, CA). Quantitative PCR for BOP1 (forward: 5'-GTGGGCTTCAACCCCTATGAG-3', reverse: 5'-CCATGCGAGAGACCTTCTCC$3^{\prime}$ ) was performed using SSO Universal SYBR (1725271; BioRad), and normalization was calculated in reference to TATA-box binding protein (forward: 5'-CCACTCACAGACTCTCACAAC-3', reverse: 5'-CTGCGGTACAATCCCAGAACT-3') and tyrosine 3-monooxygenase/ tryptophan 5-monooxygenase activation protein zeta (forward: $5^{\prime}$-TGATCCCCAATGCTTCACAAG- ${ }^{\prime}$, reverse: $5^{\prime}$ GCCAAGGTAACGGTAGTAATCT-3').

\section{Western Blot}

Western blot protocol using BioRad precast gels and nitrocellulose membrane transfer packages was performed as previously described. ${ }^{33}$ For subcellular fractionation, the nuclear and cytoplasmic fractions were separated by centrifugation following the Abcam (Cambridge, UK) protocol. Primary antibodies specific to BOP1, histone 3 (H3; 17168-1AP; Proteintech, Rosemont, IL), and $\alpha$-tubulin (Cell Signaling Technology, Danvers, MA) were diluted in 5\% bovine serum albumin/Tris-buffered saline/Tween-20 (1:5000 BOP1, 1:1000 H3, and 1:1000 $\alpha$-tubulin) and incubated overnight at $4^{\circ} \mathrm{C}$. Species-specific, horseradish-peroxidase-conjugated secondary antibodies (Bethyl Laboratories, Inc.) were incubated at room temperature for 1 hour and visualized using chemiluminescent substrate DURA (Thermo Fisher Scientific, Waltham, MA). Band intensity was quantified with ImageJ software version $1.49^{34}(\mathrm{NIH}$, Bethesda, MD; https://imagej.nih.gov/ij) after it was normalized to $\alpha$-tubulin (cytoplasmic fraction, whole cell) or H3 (nuclear fraction). To show antibody specificity, an uncropped BOP1 Western blot is included showing a single band around $83 \mathrm{kDa}$, as expected (Supplemental Figure S1A).

\section{Immunofluorescence}

Immunofluorescence was performed according to Abcam's protocol. Briefly, cells were fixed, permeabilized, and incubated with primary antibodies BOP1 (diluted 1:500) and NOP56 (diluted 1:200) for 1 hour at room temperature. Secondary antibodies [anti-rabbit conjugated to AlexaFluor 488 (A-21206; Thermo Fisher Scientific) and anti-mouse conjugated to AlexaFluor 555 (A-32773; Thermo Fisher Scientific)] were incubated for 1 hour at room temperature. DAPI was used for the nuclear stain, and images were taken at $\times 40$ magnification.

\section{Proliferation and Motility Assays}

SMARTpool ON-TARGETplus Human BOPI siRNA (siBOP1) was acquired from Dharmacon (Lafayette, CO; L014065-01-0005), with the associated siRNA nontargeting scramble control (D-001810-10-05). BCaP metastatic 1 $\left(\mathrm{BCaP}^{\mathrm{M} 1}\right)$ cells were transfected transiently with either 37.5 nmol/L siBOP1 or siRNA nontargeting scramble control using the Mirus TransIT-X2 Dynamic Delivery System (MIR 6005; Mirus, Madison, WI), according to the Mirus protocol. Proliferation was assessed by staining with MTT (M5655; Sigma-Aldrich, St. Louis, MO). To assess motility, $\mathrm{BCaP}^{\mathrm{M} 1}$ cells were plated at a seeding density of $0.25 \times 10^{6}$ cells/well and allowed to adhere overnight. The adherent cells were treated with siBOP1 or control, and a scratch was made through the cell monolayer in the center of each well as previously described. ${ }^{31}$ Images were taken at $0,6,12$, and 24 hours, and the area of the scratch was quantified with ImageJ. Statistics reflect $n=3$ biological replicates.

\section{Statistics}

Most bar graphs reflect the mean of the samples within each category with error bars showing the SEM, cBioPortal data show error bars of SD. GraphPad Prism version 8.4.1 (GraphPad Software, Inc., La Jolla, CA) was used for all statistical analyses. The Welch $t$-test was used for direct comparisons, and one-way analysis of variance with the Dunnett test was used for multicomparison statistics. For survival analysis from meta-data (accession number GSE16560), a Kaplan-Meier curve was used to represent survival in days with the robust multi-array average-normalized expression divided at the median into high $(n=140)$ and low $(n=140)$ expression. The hazard ratio was calculated using a Mantel-Haenszel test, and the $P$ value was calculated using a log-rank Mantel-Cox test.

\section{Results}

\section{B0P1 Expression Is Increased in Advanced CaP}

A meta-analysis of publicly available data sets shows significant $B O P 1$ gene expression changes in $\mathrm{CaP}$ progression and recurrence. In data acquired from Oncomine, $B O P I$ expression was increased significantly in multiple data sets when comparing prostate cancer with normal prostatic tissue (Table 1). Data mined from a GEO study assessing expression through $\mathrm{CaP}$ progression showed that $B O P 1$ expression was significantly higher in $\mathrm{CaP}$ tumors with higher Gleason scores (Gleason score, $>6 ; P<0.01$ ) and 
Table $1 \quad B O P 1$ Expression in Prostate Cancer versus Normal

\begin{tabular}{llrll}
\hline Data set & FC & $N$ & $P$ value & Significance \\
\hline Taylor prostate 3 & 1.125 & 185 & $1.97 \mathrm{E}-6$ & $* * * *$ \\
Grasso prostate & 1.365 & 122 & $1.56 \mathrm{E}-5$ & $* * * *$ \\
TCGA prostate (acinar) & 1.041 & 187 & 0.001 & $* * *$ \\
Welsh prostate & 1.790 & 34 & 0.003 & $* *$ \\
Luo prostate 2 & 1.601 & 30 & 0.004 & $* *$ \\
Singh prostate & 1.598 & 102 & 0.006 & $* *$ \\
TCGA prostate (adeno) & 1.051 & 106 & 0.008 & $* *$ \\
Varambally prostate & 1.415 & 19 & 0.033 & $*$ \\
Liu prostate & 1.068 & 57 & 0.044 & $*$ \\
\hline
\end{tabular}

All data are publicly available through the Oncomine database (https:// www.oncomine.org).

${ }^{*} P<0.05,{ }^{* *} P<0.01,{ }^{* * *} P<0.001$, and ${ }^{*} * * P<0.0001$.

adeno, adenocarcinoma; BOP1, block of proliferation 1; FC, fold change; TCGA, The Cancer Genome Atlas.

metastatic samples (mets; $P<0.0001$ ), compared with that in the benign tissue (Figure 1A). Furthermore, data from cBioPortal shows BOP1 copy number amplification in 8 independent data sets, with amplification ranging from approximately $1 \%$ of samples to more than $28 \%$ of samples within each study (Figure 1C). Three of the top four most amplified data sets for $B O P 1$ represent metastatic $\mathrm{CaP}$ (Figure 1C), with a significant increase in copy number amplification in metastases versus primary $\mathrm{CaP}$ $(P<0.0001)$ (Figure 1D). In another GEO study assessing expression in $\mathrm{CaP}$ recurrence, $B O P 1$ expression was increased significantly in recurrent samples compared with nonrecurrent samples $(P<0.05)$ (Figure 1B). Finally, $B O P 1$ expression was assessed in survival using a third GEO data set (Figure 1E). Here, overall survival was decreased significantly in samples with high $B O P 1$ expression compared with samples with low $B O P 1$ expression. Taken together, these data show increased $B O P 1$ expression through $\mathrm{CaP}$ progression and higher expression in recurrence and samples with decreased survival, suggesting that BOP1 may be a biomarker for advanced $\mathrm{CaP}$.

\section{B0P1 Expression and Localization in CaP Patient Samples}

To assess the expression and localization of $\mathrm{BOP} 1$ protein in $\mathrm{CaP}$ progression, tissue samples from several stages of $\mathrm{CaP}$ progression (benign, high-grade prostatic intraepithelial neoplasia, $\mathrm{CaP}$, and mets) were co-stained for BOP1, nucleolar marker NOP56, E-cadherin, and hematoxylin. Multiplexing these factors allows for the following: i) comparison between expression and localization of two nucleolar proteins (BOP1 and NOP56), ii) segmentation of tissue types using E-cadherin as a marker for epithelial cells, and iii) subcellular compartment segmentation with hematoxylin as a nuclear stain (Figure 2). Representative images of $\mathrm{BOP} 1$ expression in $\mathrm{CaP}$ progression show increased expression in later stages of progression, consistent with metadata (Figure 3A). When quantified, total epithelial BOP1 expression was increased significantly in $\mathrm{CaP}$ compared with that in benign tissue $(P<0.05)$ (Figure 3B). Interestingly, this increase in expression through progression appeared to coincide with a localization change from nuclear to cytoplasmic (Figure 3A). Quantification within subcellular compartments of epithelial cells showed no significant change in nuclear BOP1 through progression whereas cytoplasmic BOP1 increased significantly in $\mathrm{CaP}(P<0.001)$ and mets $(P<0.05)$ compared with benign tissue (Figure $3 \mathrm{~B})$.

Because BOP1 is a nucleolar protein, it is possible that its expression and localization through $\mathrm{CaP}$ progression is indicative of overall nucleolar changes in $\mathrm{CaP}$. To investigate the possibility that $\mathrm{BOP} 1$ is representative of overall nucleolar changes, tissue samples were co-stained with another nucleolar protein, NOP56. This protein has been established as part of the nucleolar fibrillar center and has been further validated as a marker for the nucleolus by the Human Protein Atlas initiative (www.proteinatlas.org, last accessed August 17, 2020). Consistent with prominent nucleoli in $\mathrm{CaP}$ progression and BOP1 expression, NOP56 expression increased in later stages of progression (Figure 3C). When quantified, total epithelial NOP56 expression was increased significantly in $\mathrm{CaP}(P<0.05)$ and mets $(P<0.05)$ compared with that in the benign tissue (Figure 3D). However, unlike BOP1, this increased expression through progression appeared to occur in the nucleus with a significant increase of nuclear NOP56 in CaP $(P<0.05)$ and mets $(P<0.05)$ compared with that in the benign tissue, whereas cytoplasmic NOP56 did not change (Figure 3D). Taken together, these data indicate a cellular localization change of $\mathrm{BOP} 1$ from nuclear to cytoplasmic in $\mathrm{CaP}$ progression. This localization change did not coincide with overall nucleolar changes because nucleolar marker NOP56 increased in the nucleus through $\mathrm{CaP}$ progression. Therefore, cytoplasmic BOP1, independent of nucleolar prominence, may serve as an independent biomarker for advanced stages of $\mathrm{CaP}$.

\section{Cytoplasmic BOP1 Expression and Survival}

To assess BOP1 as a biomarker for aggressive $\mathrm{CaP}$, an additional set of patient samples was stained and analyzed using clinical data for patient survival outcomes. These samples contain $\mathrm{CaP}$ cores with associated clinical data, including years of survival. In these $\mathrm{CaP}$ samples, BOP1 expression was primarily cytoplasmic, supporting data from the progression TMA (Figure 4A). In addition, BOP1 expression appeared to increase in samples with shorter survival, consistent with meta-analysis (Figure 4A). Quantification indicated that total BOP1 expression was increased significantly in the group with the shortest survival $(<6$ years) compared with the group with the longest survival $(8+$ years) $(P<0.0001)$ (Figure 4B). Importantly, quantification of cytoplasmic BOP1 showed a significant increase in expression in the group with survival of fewer than 6 years compared with the group with survival of 8 or more years $(P<0.0001)$ (Figure 4 C). A scatterplot showing BOP1 expression versus survival in nonbinned samples is shown in Supplemental Figure S1C. In addition, cytoplasmic linear regression analysis of BOP1 versus 


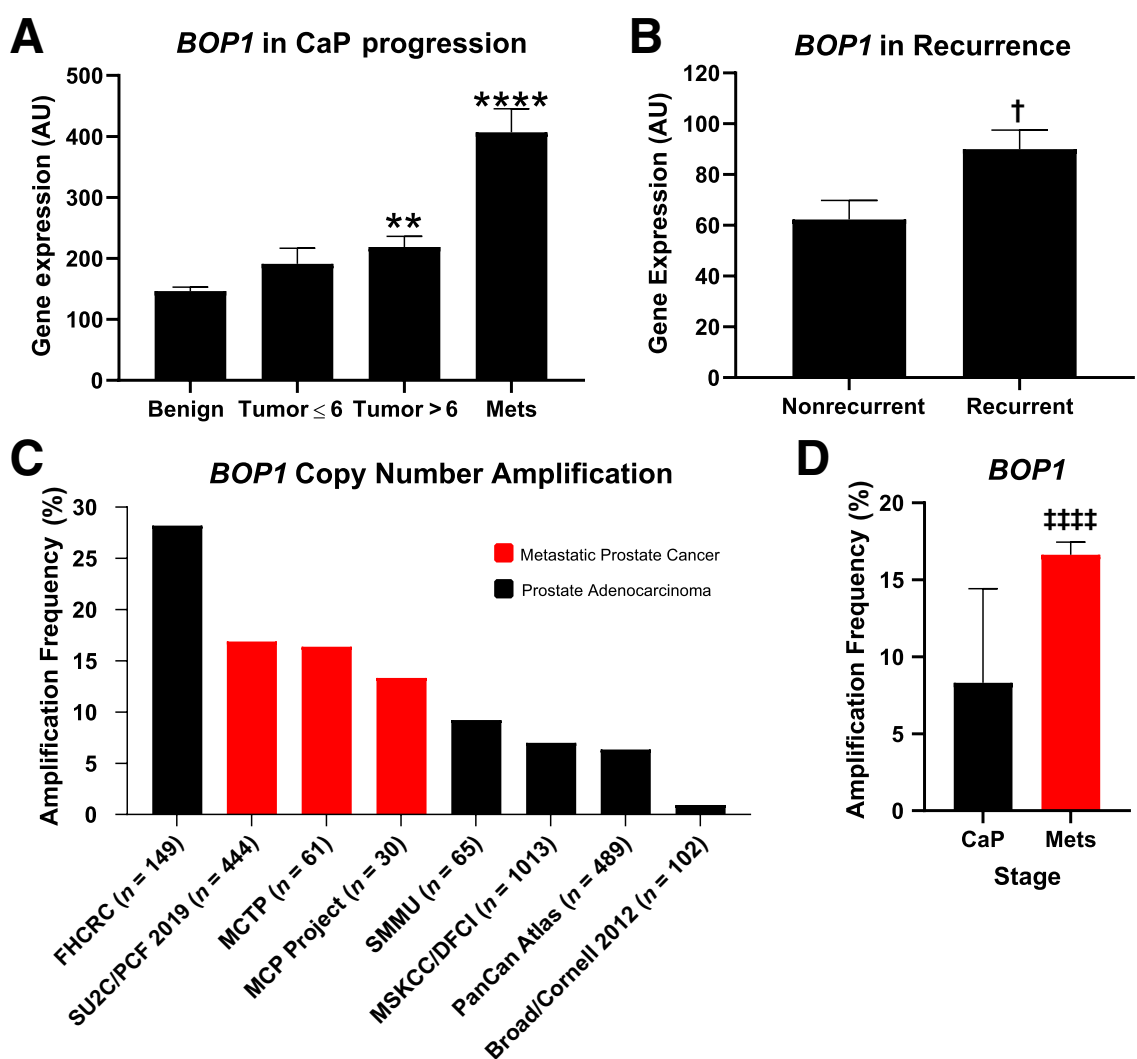

E

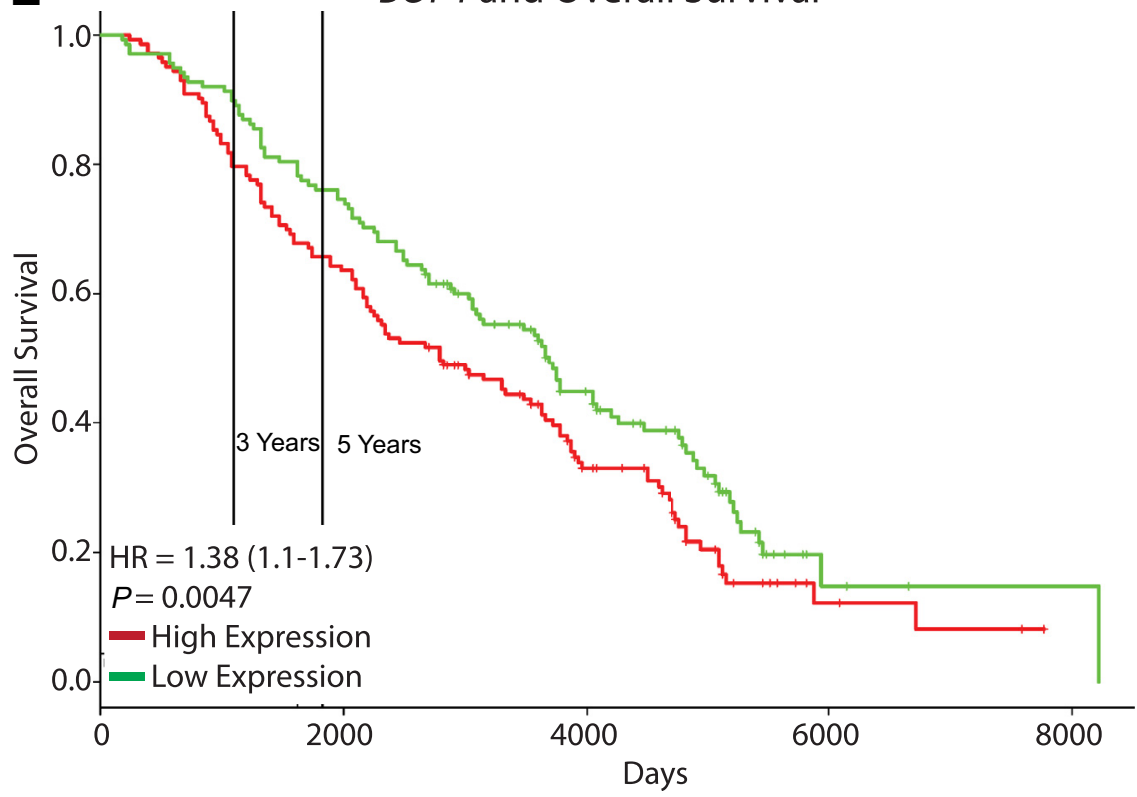

Figure 1 Block of proliferation 1 (BOP1) expression in meta-analysis of human prostate cancer (CaP). A: Gene expression analysis of publicly available Gene Expression Omnibus data showed a significant increase of BOP1 expression in aggressive tumors (Gleason score, $>6$ ) and metastases compared with benign tissue. B: Gene expression analysis of publicly available GEO data showed a significant increase of BOP1 expression in recurrent tumors versus nonrecurrent tumors. $C$ : Analysis of BOP1 copy number amplification accessed via cBioPortal showed copy number amplification of $B O P 1$ present in all data sets, with amplification frequency ranging from less than $5 \%$ to more than $25 \%$. Prostate adenocarcinoma samples are shown with black bars, and metastatic samples are shown with red bars. D: Amplification of BOP1 is increased significantly in metastatic samples compared with primary adenocarcinoma. E: Survival analysis of BOP1 expression showed a significant decrease in survival in samples with high BOP1 expression, compared with samples with low BOP1 expression $(P=0.0047) .{ }^{* *} P<0.01,{ }^{* * *} P<0.0001$ versus benign tissue; ${ }^{\dagger} P<0.05$ versus nonrecurrent; ${ }^{\ddagger \ddagger \ddagger} P<0.0001$ versus primary adenocarcinoma. AU, arbitrary units; DFCI, Dana-Farber Cancer Institute; FHCRC, Fred Hutchinson Cancer Research Center; HR, hazard ratio; MCP, metastatic prostate cancer project; MCTP, Michigan Center for Translational Pathology; Mets, metastatic tissue; MSKCC, Memorial Sloan Kettering Cancer Center; PCF, prostate cancer foundation; SMMU, Second Military Medical University; SU2C, stand up to cancer.
Gleason scores showed an increase of BOP1 in samples with higher Gleason scores $(P=0.0731)$ (Supplemental Figure S1B). Taken together, these data suggest that BOP1 expression, specifically in the cytoplasm, is associated with decreased overall survival in $\mathrm{CaP}$. Moreover, these data provide a foundation for investigation of BOP1 as a potential biomarker for aggressive $\mathrm{CaP}$ with poor overall survival.
B0P1 Expression, Localization, and Function in Models of $\mathrm{CaP}$

Because cytoplasmic BOP expression is increased in $\mathrm{CaP}$ progression and associated with decreased survival, it may be informative to understand the role of BOP1 in the cytoplasm. To address the functional role of cytoplasmic 
A
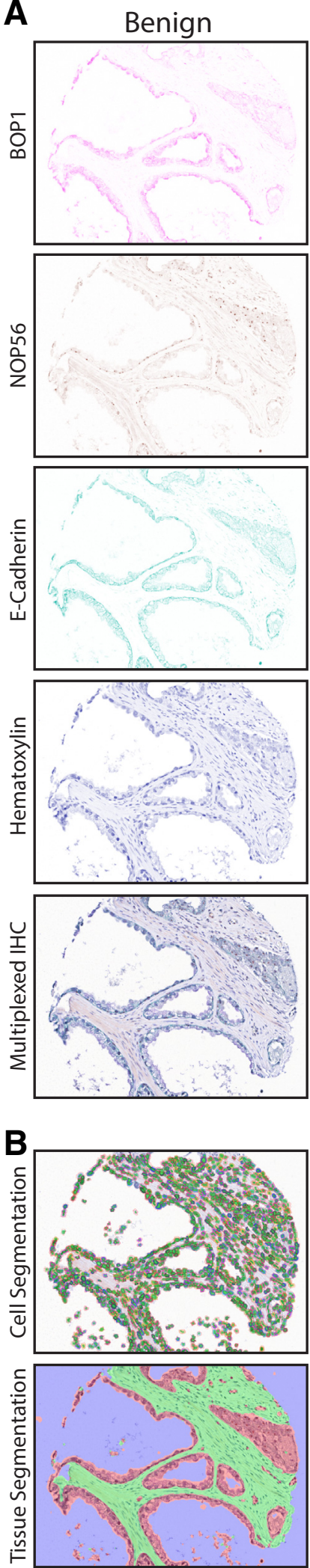

HGPIN
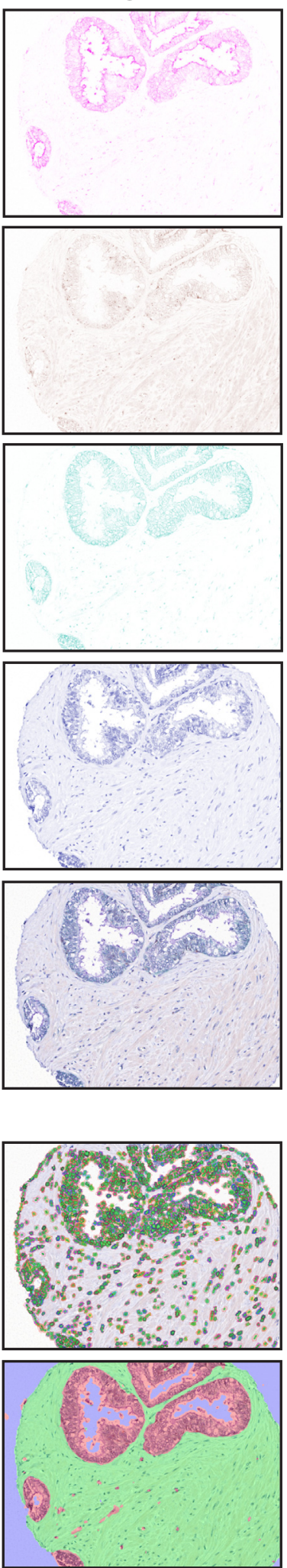

$\mathrm{CaP}$
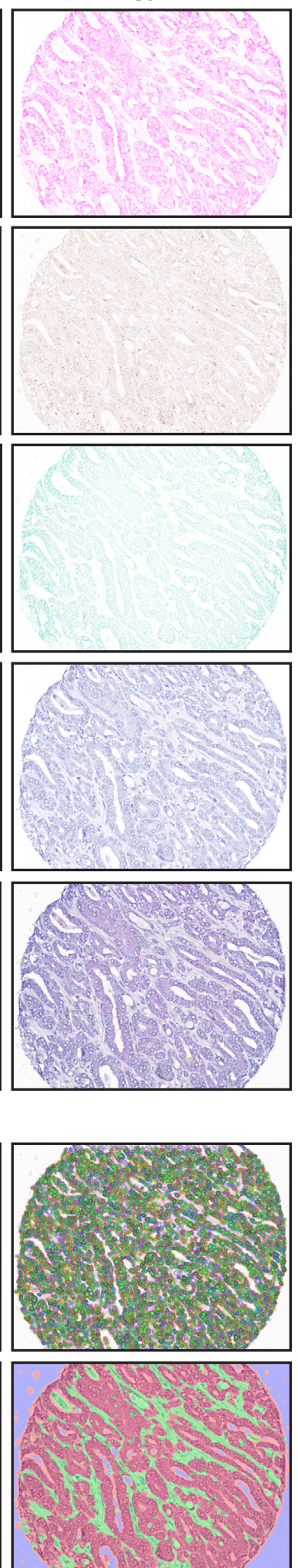

Mets
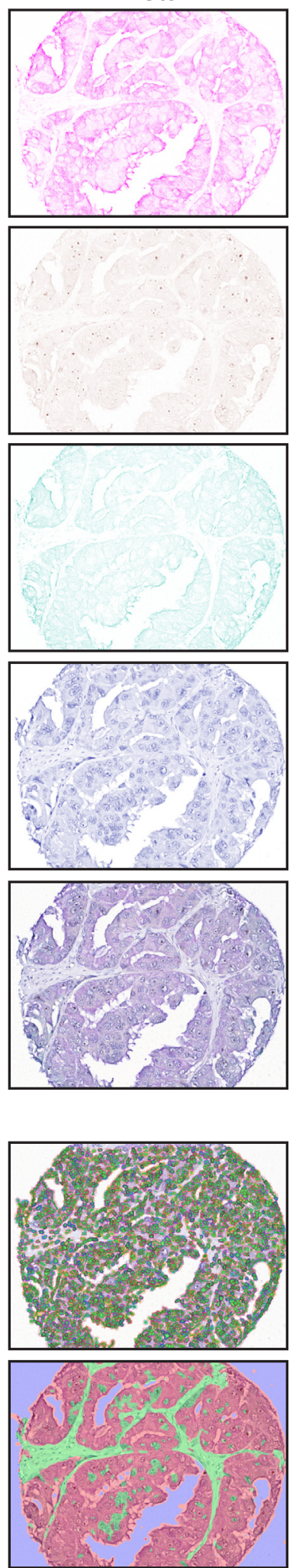

Figure 2 Multiplexed immunohistochemistry (IHC) and segmentation. A: Representative images of optically isolated images from a multiplexed IHC on tissue microarray samples from various stages of prostate cancer (CaP) progression [benign, high-grade prostatic intraepithelial neoplasia (HGPIN), CaP, and metastases (mets)]. B: Representative images of cellular compartment segmentation: nucleus (green) versus cytoplasm (multicolored) using inForm software. Similarly, tissue compartments were segmented to identify epithelium (red) versus stroma (green). Original magnification, $\times 20$. B0P1, block of proliferation 1 ; NOP56, nucleolar protein 56 . 
A

Benign
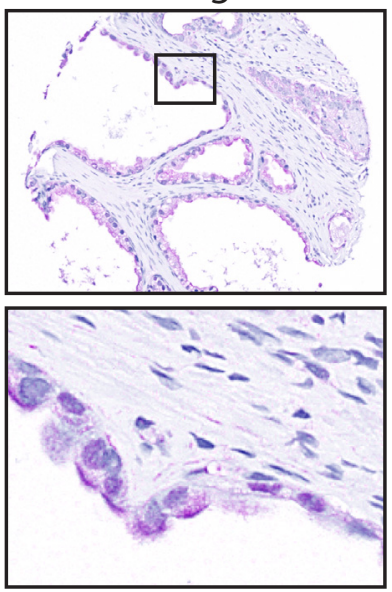

B

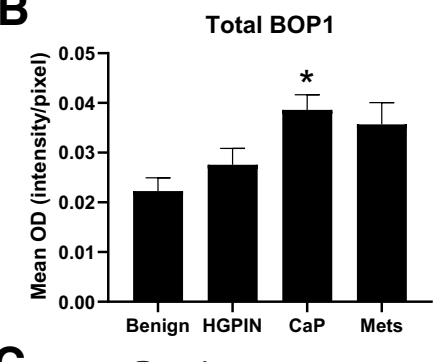

C
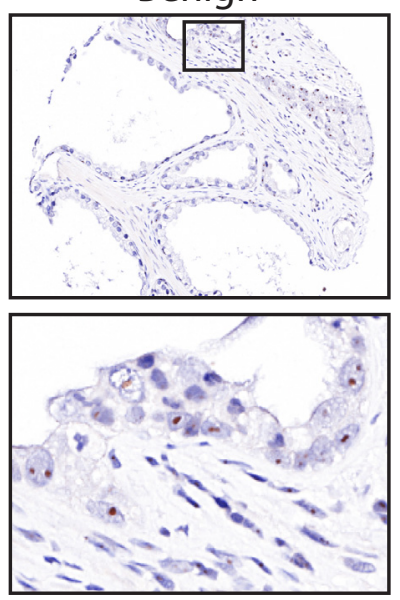

D

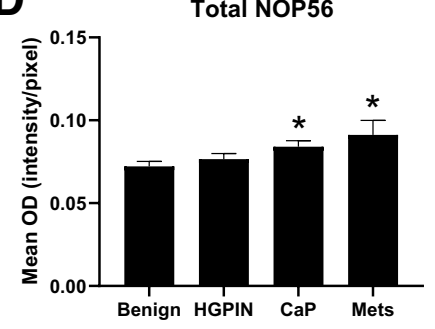

HGPIN
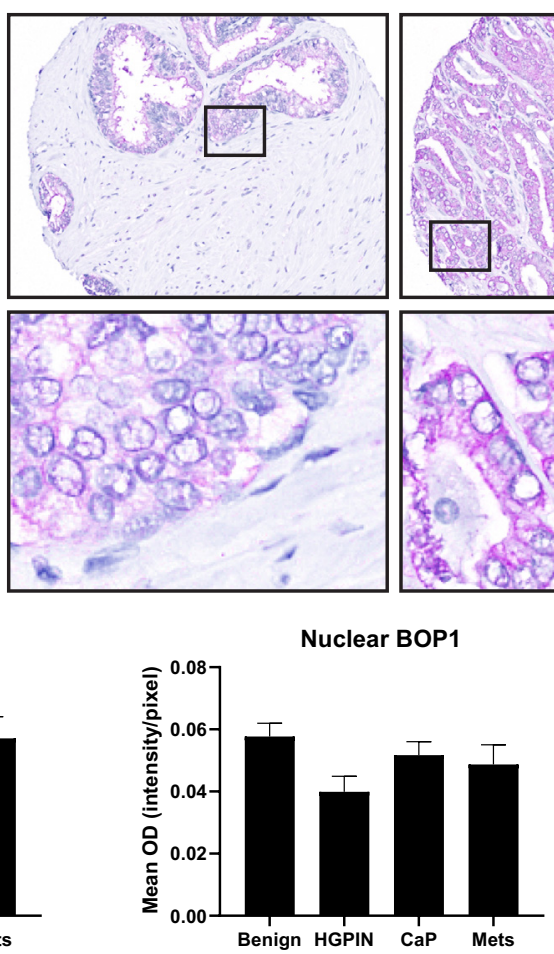

HGPIN
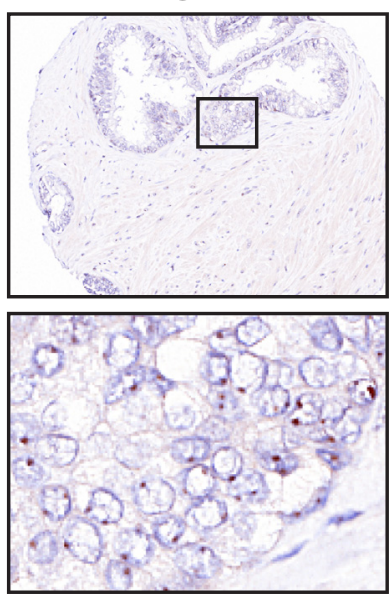

Nuclear NOP56

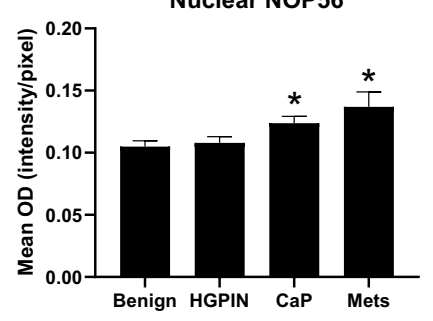

$\mathrm{CaP}$
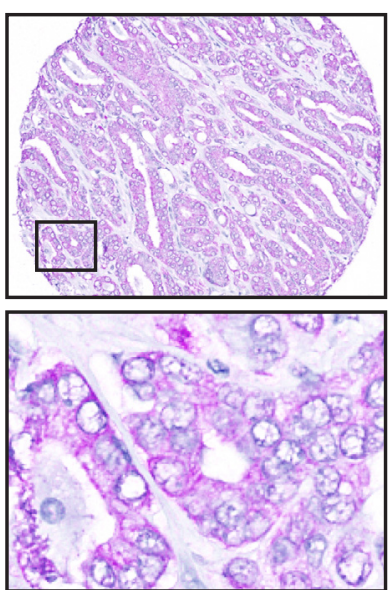

Mets
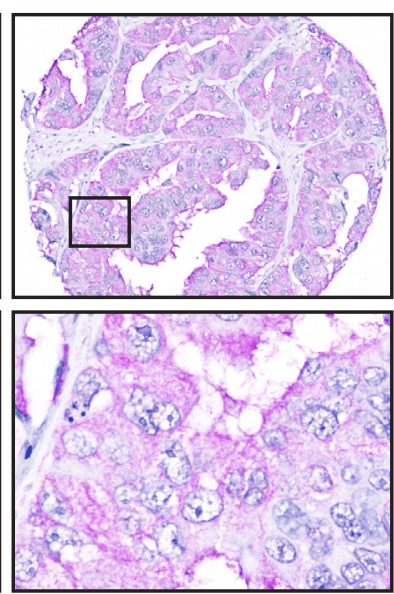

Cytoplasmic BOP1

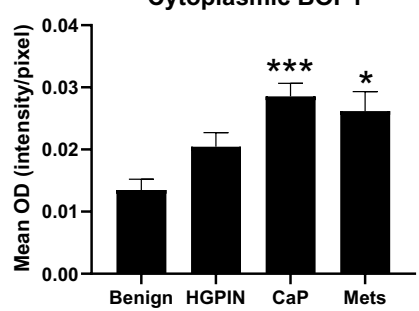

Mets
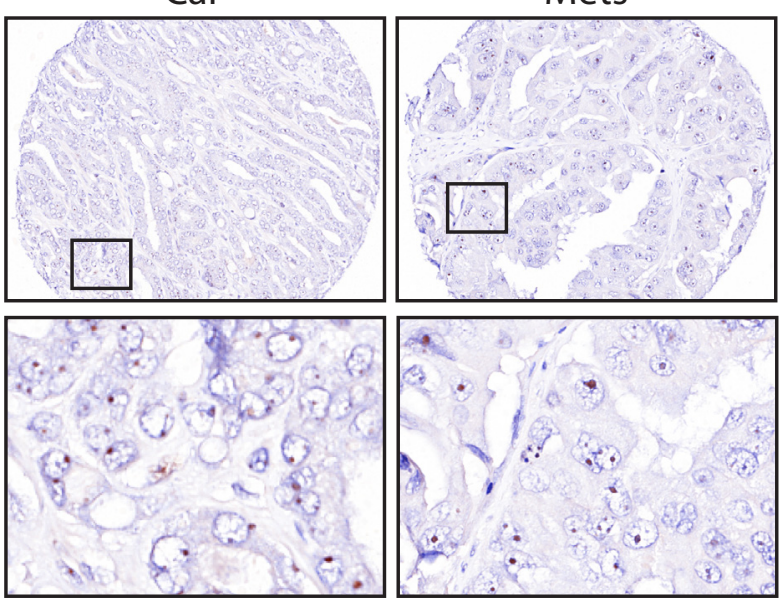

Cytoplasmic NOP56

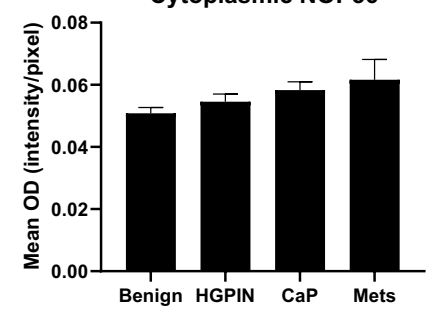

Figure 3 Block of proliferation 1 (BOP1) and nucleolar protein 56 (NOP56) expression in prostate cancer (CaP) progression. A: Representative images of BOP1 expression in CaP progression. Boxed areas in top row are shown at higher magnification in bottom row. B: Total BOP1 expression increased in CaP compared with benign tissue $(P<0.05)$. There was no significant change in nuclear B0P1 expression, but there was a significant increase in cytoplasmic B0P1 expression in CaP and metastases (mets) compared with benign tissue. C: Representative images of NOP56 expression in CaP progression. Boxed areas in top row are shown at higher magnification in bottom row. D: Total NOP56 expression and NOP56 nuclear expression were increased significantly in CaP and mets compared with benign tissue. There was no significant change in cytoplasmic N0P56 expression. ${ }^{*} P<0.05, * * * P<0.001$. Original magnification: $\times 20$ (A and C, top row); $\times 60$ (A and C, bottom row). HGPIN, high-grade prostatic intraepithelial neoplasia. 
A
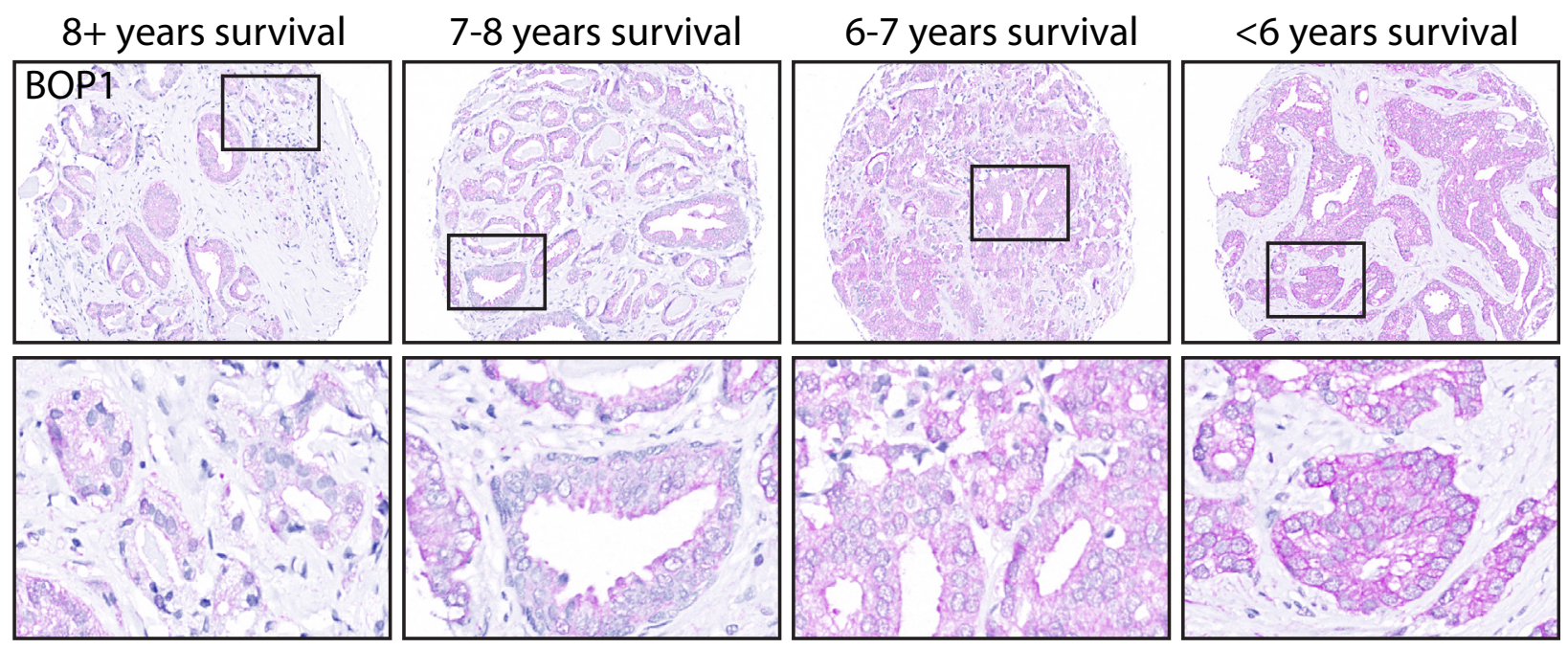

B

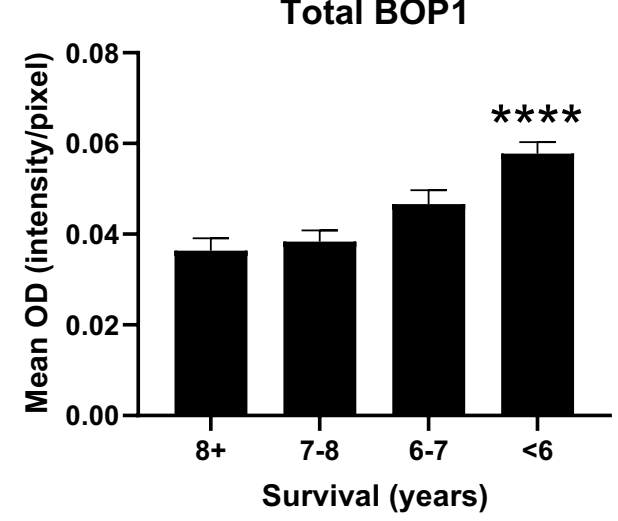

C

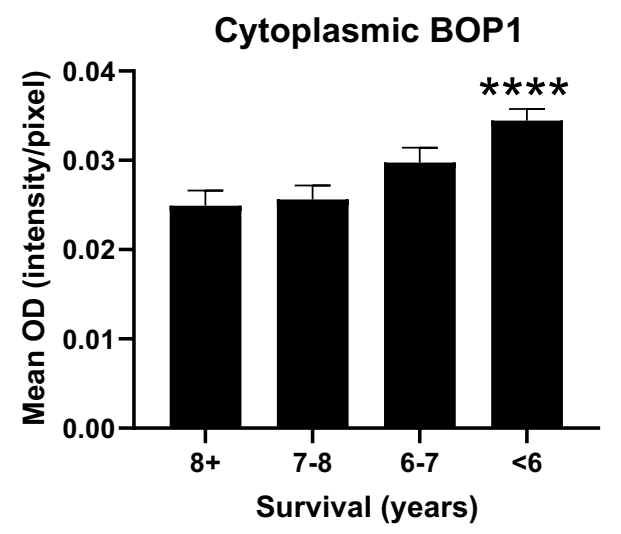

Figure 4 Block of proliferation 1 (BOP1) expression and survival. A: Representative images of BOP1 expression in human prostate cancer outcomes tissue microarray. Cores were divided into years of survival: $8+$ years, 7 to 8 years, 6 to 7 years, and fewer than 6 years. Boxed areas in top row are shown at higher magnification in bottom row. B: Quantification of total BOP1 expression in samples stratified by years of survival showed a significant increase of BOP1 expression in samples with the shortest survival ( $<6$ years) compared with the samples with the longest survival (8+ years). C: Quantification of cytoplasmic BOP1 expression showed a significant increase of cytoplasmic BOP1 in samples with the shortest survival ( $<6$ years) compared with the samples with the longest survival (8+ years). ${ }^{* * * * P}<0.0001$. Original magnification: $\times 20$ (A, top row); $\times 60$ (A, bottom row). 0D, optical density.

BOP1, its expression and localization were assessed in several CaP cell line models. At the RNA level, BOP1 expression was increased significantly in the $\mathrm{CaP}$ cell lines metastatic/aggressive primary $\mathrm{CaP}\left(\mathrm{BCaP}^{\mathrm{T} 10} ; P<0.05\right)$, $\operatorname{BCaP}^{\mathrm{M} 1}(P<0.05)$, DU145 $(P<0.01), \operatorname{LNCaP}(P<0.01)$, and PC3 $(P<0.01)$ compared with the nontumorigenic cell line BPH1 (Figure 5A). To assess BOP1 protein expression changes through $\mathrm{CaP}$ progression, the $\mathrm{BCaP}$ model was used because of its derivation from a single patient, allowing maintenance of syngeneity for meaningful comparisons between disease stages. ${ }^{31}$ In this model, BOP1 protein expression and localization were assessed in nonmetastatic/ indolent primary $\mathrm{CaP}\left(\mathrm{BCaP}^{\mathrm{T} 1}\right)$, compared with $\mathrm{BCaP}^{\mathrm{T} 10}$ and $\mathrm{BCaP}^{\mathrm{M} 1} \cdot{ }^{31}$ Western blot analysis showed an increase in total $\mathrm{BOP} 1$ protein expression in $\mathrm{BCaP}^{\mathrm{T} 10}$ and $\mathrm{BCaP}^{\mathrm{M} 1}$ compared with $\mathrm{BCaP}^{\mathrm{T} 1}$ (Figure 5, B and C). Similar to data from patient samples, the increase in BOP1 expression occurred in the cytoplasmic fraction, although nuclear BOP1 decreased (Figure 5, B and C). Using immunofluorescence, $\mathrm{BOP} 1$ localization was visualized in the $\mathrm{BCaP}$ model. Here, BOP1 co-localized with nucleolar marker NOP56 in $\mathrm{BCaP}^{\mathrm{T} 1}$ and $\mathrm{BCaP}^{\mathrm{T} 10}$ in puncta in the nucleus, suggesting localization to nucleoli (Figure 5D). However, in $\mathrm{BCaP}^{\mathrm{T} 10}$ and $\mathrm{BCaP}^{\mathrm{M} 1}$, BOP1 was localized to the cytoplasm, consistent with patient data for metastatic $\mathrm{CaP}$ (Figure 5D). To assess the functional role of BOP1 in advanced $\mathrm{CaP}$, siRNA was used to genetically knock down $B O P 1$ in $\mathrm{BCaP}^{\mathrm{M} 1}$ cells. Western blot confirmed a robust knockdown of $B O P 1$ with siRNA targeting BOP1 (siBOPl) compared with nontargeting scramble siRNA control (Figure 5E). Results from a proliferation assay showed that BOP1 knockdown decreased BOP1 proliferation significantly compared with controls (Figure 5F). Similarly, siBOP1 decreased motility significantly compared with 


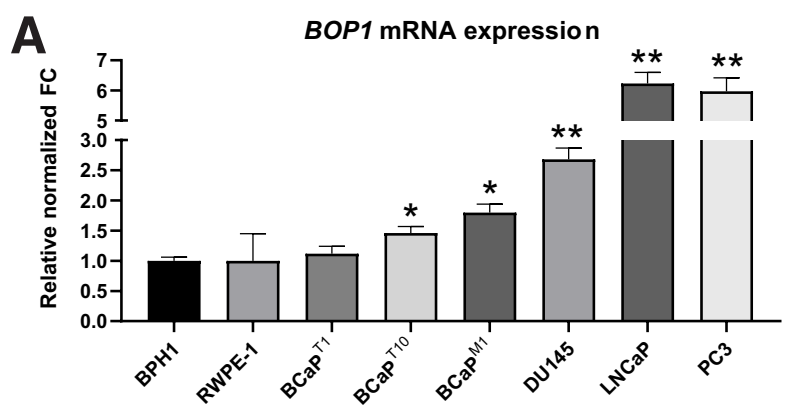

\section{B}

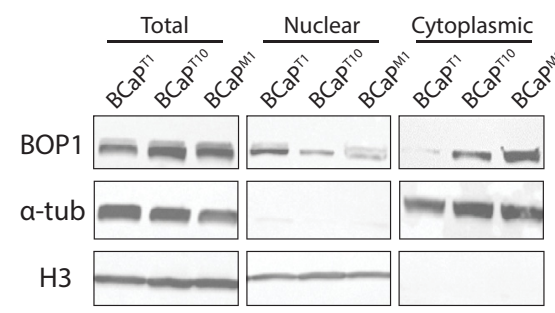

C
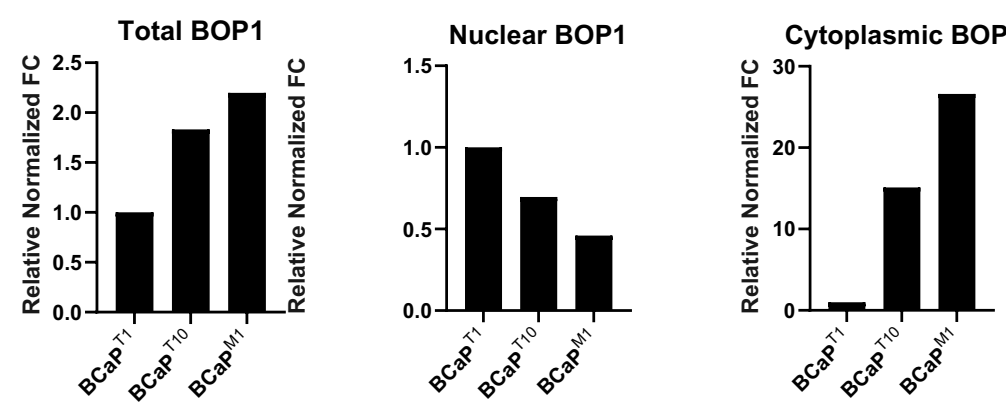

D
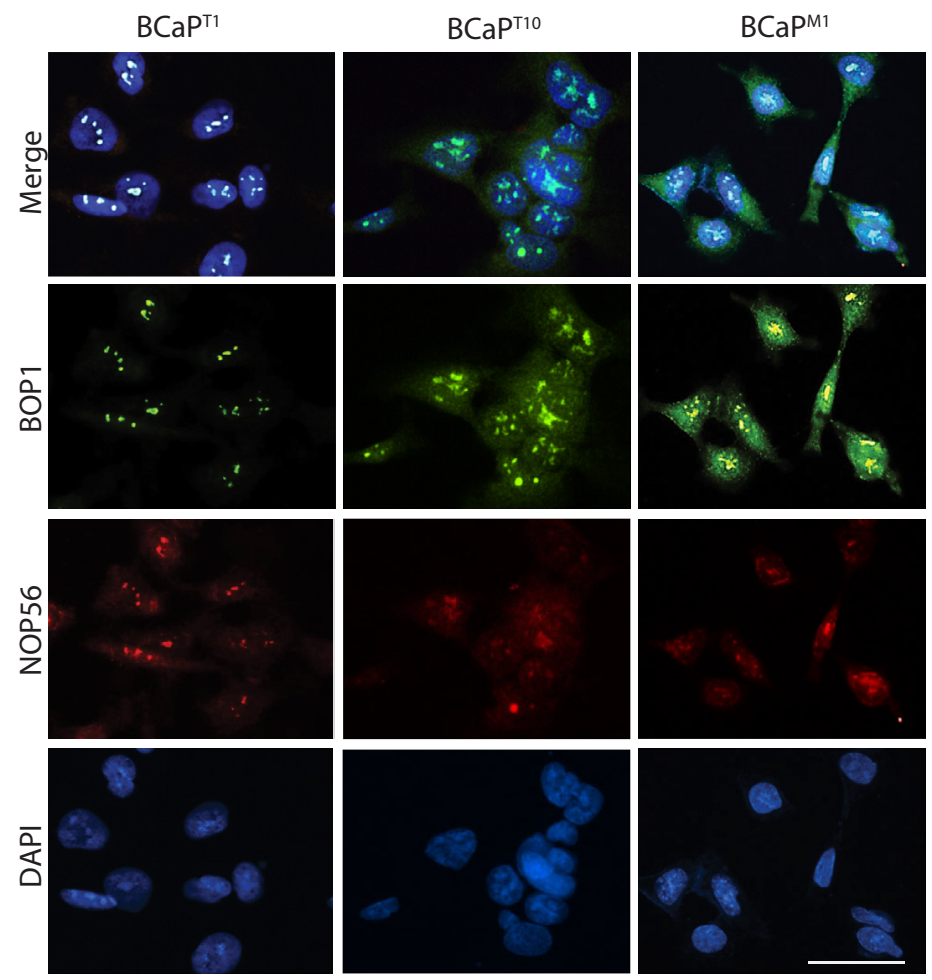

E

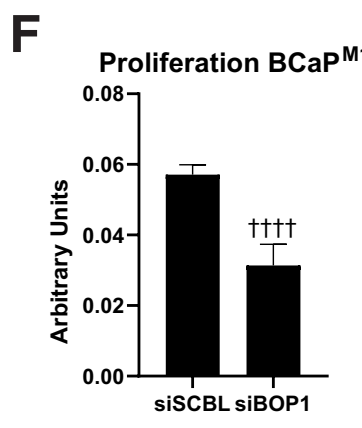

G
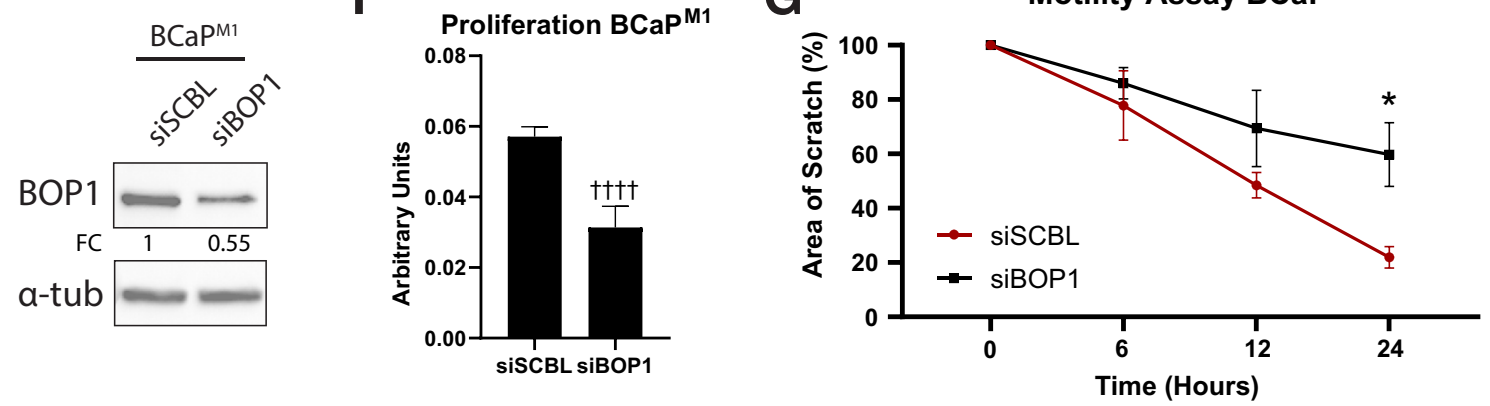
control (Figure 5G and Supplemental Figure S1D), suggesting that $B O P 1$ also may play a role in mechanisms of cell motility. In addition, because the BOP1 expression in $\mathrm{BCaP}^{\mathrm{M} 1}$ is predominantly cytoplasmic, the decrease of proliferation and motility with BOP1 knockdown may be attributed to a loss of cytoplasmic BOPl function. Taken together, these data suggest that the $\mathrm{BCaP}$ model accurately represents human $\mathrm{CaP}$ progression for $\mathrm{BOP} 1$ expression/ localization and provides a foundation for further assessment of the functional significance of cytoplasmic BOP1.

\section{Discussion}

Distinguishing between indolent and aggressive $\mathrm{CaP}$ has surged to the forefront of $\mathrm{CaP}$ research in recent years in an attempt to better inform treatment strategies and improve patient survival. Although some histologic and biochemical changes have been associated with advancement of $\mathrm{CaP}$ [ie, Gleason score/grade, clinical $\mathrm{T}$ stage, prostate-specific antigen (PSA), and prostate health index], biomarkers differentiating indolent versus aggressive $\mathrm{CaP}$ are scarce and lack ubiquitous use in the clinic. ${ }^{35}$ Nucleolar prominence has been recognized as a histologic marker for $\mathrm{CaP}$ and $\mathrm{CaP}$ progression for decades ${ }^{9,10}$; however, the functional implications of expression/localization changes for specific nucleolar proteins has not been studied in detail. Here, expression and localization of nucleolar protein BOP1 was explored both in $\mathrm{CaP}$ progression and in its association with clinical outcomes such as survival. To the best of our knowledge, this is the first publication to investigate the expression and localization of $\mathrm{BOP} 1$ expression in $\mathrm{CaP}$, and its potential implications as a biomarker.

Historically, biomarkers for the prognosis of $\mathrm{CaP}$ have been difficult to identify and incorporate into clinical use. Although several $\mathrm{CaP}$ biomarkers have been characterized including PSA, phosphatase and tensin homolog (PTEN), ${ }^{36}$ transmembrane protease serine 2:v-ets erythroblastosis virus E26 oncogene homolog (TMPRSS2:ERG), ${ }^{37}$ and androgen receptor variant 7 (ARv7), their prognostic values are limited, presenting a need for additional biomarkers. PSA is a serum biomarker that, when increased, indicates the presence of $\mathrm{CaP}$; however, because PSA cannot stratify $\mathrm{CaP}$ prognosis, its widespread clinical use has contributed to overdiagnosis and overtreatment of CaP. Loss of PTEN has also been associated with $\mathrm{CaP}$ progression, with PTEN mutation or deletion identified in $20 \%$ of primary $\mathrm{CaP}$ and increasing to up to $50 \%$ of aggressive/recurrent $\mathrm{CaP}$ with PTEN loss. ${ }^{36}$ More recently, a gene fusion allowing TMPRSS2-driven ERG expression was identified in approximately $50 \%$ of $\mathrm{CaP}$ with some controversy around its prognostic significance. ${ }^{38,39}$ Emergence of Arv7 expression was also identified in advanced $\mathrm{CaP}$ in approximately $18 \%$ to $30 \%$ of samples, which has been shown to provide a mechanism for therapy resistance. ${ }^{40}$ Finally, several preliminary studies have identified potential biomarkers for advanced disease including protein tyrosine phosphatase $4 \mathrm{~A} 3$ and prostate cancer-associated $3 .^{41,42}$ Despite exhaustive efforts, the panel of biomarkers for aggressive disease is incomplete, and identification of additional biomarkers is necessary to improve treatment strategies.

In the present study, the expression, localization, and prognostic significance of $\mathrm{BOP} 1$ in $\mathrm{CaP}$ progression was investigated. Recently, nucleolar proteins were implicated in $\mathrm{CaP}$ with the investigation of small nucleolar RNA. ${ }^{15}$ Because BOP1 has been identified as part of a nucleolar complex, its expression and localization in $\mathrm{CaP}$ could provide insight into the histologic phenomenon of nucleolar prominence in $\mathrm{CaP}$. However, these data indicate a localization change of BOP1 from nuclear to cytoplasmic that appears to be independent of nucleolar integrity. This localization change was associated with advanced disease and decreased survival. Although little is known about the significance of cytoplasmic BOP1, one study showed that BOP1 expression in the cytoplasm can occur owing to a molecular imbalance of BOP1 in relation to other components of the PeBoW complex. Nucleolar localization of BOP1 was dependent on PES1, and overexpression of BOP1 without PES1 resulted in accumulation of BOP1 in the cytoplasm. ${ }^{17}$ In other studies, BOP1 was implicated in increasing cell motility by activating $\mathrm{Rho}^{20}$ or decreasing apoptosis by inhibiting $\mathrm{p} 53,{ }^{43}$ potentially supporting a role for BOP1 in advanced/metastatic disease.

This potential role for cytoplasmic BOP1 in metastasis can be addressed using the $\mathrm{BCaP}$ cell lines. This model is ideal for studying $\mathrm{CaP}$ progression for several reasons. First, the cell lines that represent each stage of $\mathrm{CaP}$ progression (nontumorigenic, indolent tumor, aggressive tumor, metastases) in this model are all derived from a single cell taken from a patient sample. ${ }^{31}$ Therefore, these cell lines are syngeneic, allowing meaningful gene expression

\footnotetext{
Figure 5 Block of proliferation 1 (BOP1) expression, localization, and function in prostate cancer (CaP) progression models. A: BOP1 mRNA expression was assessed in a panel of prostate cell line models including benign [benign prostatic hyperplasia cell line 1 (BPH1), prostate epithelial transformed by HPV (RWPE-1)] and $\mathrm{CaP}\left[\right.$ nonmetastatic/indolent primary $\mathrm{CaP}\left(\mathrm{BCaP}^{\mathrm{T}}\right)$, metastatic/aggressive primary $\mathrm{CaP}\left(\mathrm{BCaP} \mathrm{P}^{\top 10}\right), \mathrm{BCaP}$ metastatic $1\left(\mathrm{BCaP}^{\mathrm{M} 1}\right)$, prostate cancer brain metastasis (DU145), lymph node carcinoma for the prostate (LNCaP), and prostate cancer bone metastasis (PC3)], where BOP1 was increased significantly in $\mathrm{BCaP}^{\mathrm{T} 10}, \mathrm{BCaP} \mathrm{P}^{\mathrm{M1}}, \mathrm{DU} 145, \mathrm{LNCaP}$, and $\mathrm{PC} 3$ compared with BPH1. B: B0P1 protein expression was assessed in the BCaP progression cell lines, where total B0P1 and cytoplasmic BOP1 was increased in aggressive $\mathrm{CaP}\left(\mathrm{BCaP}^{\mathrm{T} 10}\right)$ and metastatic $\mathrm{CaP}\left(\mathrm{BCaP}^{\mathrm{M} 1}\right)$ compared with indolent $\mathrm{CaP}\left(\mathrm{BCaP}^{\mathrm{T} 1}\right)$. C: $\mathrm{Quantification}$ of subcellular fractionation Western blot analysis from panel B. D: Immunofluorescent staining for B0P1 (green) and nucleolar marker nucleolar protein 56 (NOP56) (red) in the BCaP cell lines showed a BOP1 localization change from nucleoli in indolent CaP to the cytoplasm in metastatic CaP. Nuclei were stained with DAPI (blue). E: Western blot showed robust BOP1 knockdown in metastatic CaP cell line BCaP ${ }^{\mathrm{M} 1}$ with siRNA targeting BOP1 (siBOP1) compared with nontargeting scramble siRNA control (siSCBL). $\alpha$-tubulin ( $\alpha$-tub) was used as a loading control. F: siBOP1 significantly decreased proliferation of BCaP ${ }^{M 1}$ cells compared with control. G: siBOP1 significantly decreased motility of $\mathrm{BCaP}{ }^{M 1}$ cells compared with control at 24 hours. ${ }^{\star} P<0.05,{ }^{* * P} P<0.01$ versus $\mathrm{BPH} 1 ;{ }^{\dagger} P<$ $0.05,{ }^{\dagger \dagger \dagger} P<0.0001$ versus siSCBL. Scale bar $=25 \mu \mathrm{m}$ (D). FC, fold change; H3, histone 3 .
} 
comparisons between stages. ${ }^{31}$ Second, important genetic and molecular changes are associated with disease progression, including the TMPRSS2:ERG gene fusion, were observed in this model, this being the only $\mathrm{CaP}$ model to conserve this fusion event. ${ }^{31}$ Finally, not only do the $\mathrm{BCaP}$ cell lines accurately model human BOP1 expression and localization change from the nucleolus to the cytoplasm, but the genetic inhibition of BOP1 also decreased proliferation and motility in this model. Taken together, these characteristics and expression profiles suggest the $\mathrm{BCaP}$ model would be ideal for further functional analysis of BOP1 in $\mathrm{CaP}$ progression.

This study characterized BOP1 expression and localization in $\mathrm{CaP}$ progression, and further suggested a prognostic value for BOP1 cytoplasmic expression in metastatic $\mathrm{CaP}$ in association with decreased survival. Based on a search of the literature, there may be a functional role of cytoplasmic BOP1 to induce cell motility via RhoA, which may lead to metastasis. Similarly, BOP1 in CaP may be functioning to inhibit apoptosis by associating with p53. The present results show that genetic knockdown of BOP1 expression decreased proliferation and motility in advanced $\mathrm{CaP}$. There is a clinical need for additional prognostic biomarkers to differentiate indolent versus aggressive $\mathrm{CaP}$, and observation from the current study of BOP1 localization to the cytoplasm in metastatic $\mathrm{CaP}$ provides a basis for further investigation of BOP1 as a biomarker in this context. Follow-up studies addressing the activity of BOP1 in the cytoplasm may provide additional insight into the molecular changes that occur as $\mathrm{CaP}$ progresses, and potentially serve as a foundation for targeting BOP1 in metastatic CaP.

\section{Acknowledgments}

We thank the University of Wisconsin Translational Research Initiatives in Pathology Laboratory for use of its facilities and services, and Dr. Glen Allen for assistance with statistical analysis. We additionally thank Dr. Teresa Liu, Dr. Petra Popovics, Dr. Debra Garvey, Dalton McLean, Kristen Uchtmann, and Christian Ortiz-Hernandez for manuscript editing.

\section{Supplemental Data}

Supplemental material for this article can be found at http://doi.org/10.1016/j.ajpath.2020.09.010.

\section{References}

1. Howlader NNA, Krapcho M, Miller D, Brest A, Yu M, Ruhl J, Tatalovich Z, Mariotto A, Lewis DR, Chen HS, Feuer EJ, Cronin KA: SEER cancer statistics review, 1975-2016. National Cancer Institute. Available at, https://seer.cancer.gov/csr/1975_2016/ (accessed September 3, 2020)

2. Siegel RL, Miller KD, Jemal A: Cancer statistics, 2020. CA Cancer J Clin 2020, 70:7-30
3. Loeb S, Bjurlin MA, Nicholson J, Tammela TL, Penson DF, Carter HB, Carroll P, Etzioni R: Overdiagnosis and overtreatment of prostate cancer. Eur Urol 2014, 65:1046-1055

4. Aizer AA, Gu X, Chen MH, Choueiri TK, Martin NE, Efstathiou JA, Hyatt AS, Graham PL, Trinh QD, Hu JC, Nguyen PL: Cost implications and complications of overtreatment of low-risk prostate cancer in the United States. J Natl Compr Cancer Netw 2015, 13:61-68

5. Bratt O, Folkvaljon Y, Hjalm Eriksson M, Akre O, Carlsson S, Drevin L, Franck Lissbrant I, Makarov D, Loeb S, Stattin P: Undertreatment of men in their seventies with high-risk nonmetastatic prostate cancer. Eur Urol 2015, 68:53-58

6. Lunardi P, Ploussard G, Grosclaude P, Roumiguie M, Soulie M, Beauval JB, Malavaud B: Current impact of age and comorbidity assessment on prostate cancer treatment choice and over/undertreatment risk. World J Urol 2017, 35:587-593

7. Klotz LH: Active surveillance with selective delayed intervention: walking the line between overtreatment for indolent disease and undertreatment for aggressive disease. Can J Urol 2005, Suppl 1: 53-57. discussion 101-102

8. Pathirana T, Hayen A, Doust J, Glasziou P, Bell K: Lifetime risk of prostate cancer overdiagnosis in Australia: quantifying the risk of overdiagnosis associated with prostate cancer screening in Australia using a novel lifetime risk approach. BMJ Open 2019, 9:e022457

9. Fischer AH, Bardarov S Jr, Jiang Z: Molecular aspects of diagnostic nucleolar and nuclear envelope changes in prostate cancer. J Cell Biochem 2004, 91:170-184

10. Tannenbaum M, Tannenbaum S, deSanctis PN, Olsson CA: Prognostic significance of nucleolar surface area in prostate cancer. Urology 1982, 19:546-551

11. Derenzini M, Trere D, Pession A, Govoni M, Sirri V, Chieco P: Nucleolar size indicates the rapidity of cell proliferation in cancer tissues. J Pathol 2000, 191:181-186

12. Strezoska Z, Pestov DG, Lau LF: Functional inactivation of the mouse nucleolar protein Bop1 inhibits multiple steps in pre-rRNA processing and blocks cell cycle progression. J Biol Chem 2002, 277:29617-29625

13. Boisvert FM, van Koningsbruggen S, Navascues J, Lamond AI: The multifunctional nucleolus. Nat Rev Mol Cell Biol 2007, 8:574-585

14. Orsolic I, Jurada D, Pullen N, Oren M, Eliopoulos AG, Volarevic S: The relationship between the nucleolus and cancer: current evidence and emerging paradigms. Semin Cancer Biol 2016, 37-38:36-50

15. Gong J, Li Y, Liu CJ, Xiang Y, Li C, Ye Y, Zhang Z, Hawke DH, Park PK, Diao L, Putkey JA, Yang L, Guo AY, Lin C, Han L: A pancancer analysis of the expression and clinical relevance of small nucleolar RNAs in human cancer. Cell Rep 2017, 21:1968-1981

16. Strezoska Z, Pestov DG, Lau LF: Bop1 is a mouse WD40 repeat nucleolar protein involved in 28S and 5. 8S RRNA processing and 60S ribosome biogenesis. Mol Cell Biol 2000, 20:5516-5528

17. Rohrmoser M, Holzel M, Grimm T, Malamoussi A, Harasim T, Orban M, Pfisterer I, Gruber-Eber A, Kremmer E, Eick D: Interdependence of Pes1, Bop1, and WDR12 controls nucleolar localization and assembly of the PeBoW complex required for maturation of the 60S ribosomal subunit. Mol Cell Biol 2007, 27:3682-3694

18. Pestov DG, Strezoska Z, Lau LF: Evidence of p53-dependent crosstalk between ribosome biogenesis and the cell cycle: effects of nucleolar protein Bop1 on G(1)/S transition. Mol Cell Biol 2001, 21 : $4246-4255$

19. Killian A, Sarafan-Vasseur N, Sesboue R, Le Pessot F, Blanchard F, Lamy A, Laurent M, Flaman JM, Frebourg T: Contribution of the BOP1 gene, located on $8 \mathrm{q} 24$, to colorectal tumorigenesis. Genes Chromosomes Cancer 2006, 45:874-881

20. Chung KY, Cheng IK, Ching AK, Chu JH, Lai PB, Wong N: Block of proliferation 1 (BOP1) plays an oncogenic role in hepatocellular carcinoma by promoting epithelial-to-mesenchymal transition. Hepatology 2011, 54:307-318

21. Gupta R, Bugide S, Wang B, Green MR, Johnson DB, Wajapeyee N: Loss of BOP1 confers resistance to BRAF kinase inhibitors in 
melanoma by activating MAP kinase pathway. Proc Natl Acad Sci U S A 2019, 116:4583-4591

22. Rhodes DR, Yu J, Shanker K, Deshpande N, Varambally R, Ghosh D, Barrette T, Pander A, Chinnaiyan AM: ONCOMINE: a cancer microarray database and integrated data-mining platform. Neoplasia 2004, 6:1-6

23. Cerami E, Gao J, Dogrusoz U, Gross BE, Sumer SO, Aksoy BA, Jacobsen A, Byrne CJ, Heuer ML, Larsson E: The cBio cancer genomics portal: an open platform for exploring multidimensional cancer genomics data. Cancer Discov 2012, 2:401-404

24. Gao J, Aksoy BA, Dogrusoz U, Dresdner G, Gross B, Sumer SO, Sun Y, Jacobsen A, Sinha R, Larsson E: Integrative analysis of complex cancer genomics and clinical profiles using the cBioPortal. Sci Signal 2013, 6:pl1

25. Chandran UR, Ma C, Dhir R, Bisceglia M, Lyons-Weiler M, Liang W, Michalopoulos G, Becich M, Monzon FA: Gene expression profiles of prostate cancer reveal involvement of multiple molecular pathways in the metastatic process. BMC Cancer 2007, 7:64

26. Sun Y, Goodison S: Optimizing molecular signatures for predicting prostate cancer recurrence. Prostate 2009, 69:1119-1127

27. Sboner A, Demichelis F, Calza S, Pawitan Y, Setlur SR, Hoshida Y, Perner S, Adami HO, Fall K, Mucci LA, Kantoff PW, Stampfer M, Andersson SO, Varenhorst E, Johansson JE, Gerstein MB, Golub TR, Rubin MA, Andren O: Molecular sampling of prostate cancer: a dilemma for predicting disease progression. BMC Med Genomics 2010, $3: 8$

28. Huang W, Hennrick K, Drew S: A colorful future of quantitative pathology: validation of Vectra technology using chromogenic multiplexed immunohistochemistry and prostate tissue microarrays. Hum Pathol 2013, 44:29-38

29. Bauman TM, Vezina CM, Ricke EA, Halberg RB, Huang W, Peterson RE, Ricke WA: Expression and colocalization of $\beta$-catenin and lymphoid enhancing factor-1 in prostate cancer progression. Hum Pathol 2016, 51:124-133

30. Hayward SW, Wang Y, Cao M, Hom YK, Zhang B, Grossfeld GD, Sudilovsky D, Cunha GR: Malignant transformation in a nontumorigenic human prostatic epithelial cell line. Cancer Res 2001, 61: $8135-8142$

31. Liu TT, Ewald JA, Ricke EA, Bell R, Collins C, Ricke WA: Modeling human prostate cancer progression in vitro. Carcinogenesis 2019, 40:893-902

32. Hayward S, Dahiya R, Cunha G, Bartek J, Deshpande N, Narayan P: Establishment and characterization of an immortalized but non-transformed human prostate epithelial cell line: BPH-1. In Vitro Cell Dev Biol Anim 1995, 31:14-24

33. Towbin H, Staehelin T, Gordon J: Electrophoretic transfer of proteins from polyacrylamide gels to nitrocellulose sheets: procedure and some applications. Proc Natl Acad Sci U S A 1979, 76:4350-4354

34. Schneider CA, Rasband WS, Eliceiri KW: NIH Image to ImageJ: 25 years of image analysis. Nat Methods 2012, 9:671

35. Kohaar I, Petrovics G, Srivastava S: A rich array of prostate cancer molecular biomarkers: opportunities and challenges. Int J Mol Sci 2019, 20:1813

36. Jamaspishvili T, Berman DM, Ross AE, Scher HI, De Marzo AM, Squire JA, Lotan TL: Clinical implications of PTEN loss in prostate cancer. Nat Rev Urol 2018, 15:222-234

37. Wang Z, Wang Y, Zhang J, Hu Q, Zhi F, Zhang S, Mao D, Zhang Y, Liang H: Significance of the TMPRSS2:ERG gene fusion in prostate cancer. Mol Med Rep 2017, 16:5450-5458

38. Nam RK, Sugar L, Wang Z, Yang W, Kitching R, Klotz LH, Venkateswaran V, Narod SA, Seth A: Expression of TMPRSS2:ERG gene fusion in prostate cancer cells is an important prognostic factor for cancer progression. Cancer Biol Ther 2007, 6:40-45

39. Pettersson A, Graff RE, Bauer SR, Pitt MJ, Lis RT, Stack EC, Martin NE, Kunz L, Penney KL, Ligon AH, Suppan C, Flavin R, Sesso HD, Rider JR, Sweeney C, Stampfer MJ, Fiorentino M, Kantoff PW, Sanda MG, Giovannucci EL, Ding EL, Loda M, Mucci LA: The TMPRSS2:ERG rearrangement, ERG expression, and prostate cancer outcomes: a cohort study and meta-analysis. Cancer Epidemiol Biomarkers Prev 2012, 21:1497-1509

40. Dehm SM, Schmidt LJ, Heemers HV, Vessella RL, Tindall DJ: Splicing of a novel androgen receptor exon generates a constitutively active androgen receptor that mediates prostate cancer therapy resistance. Cancer Res 2008, 68:5469-5477

41. Edwards DR, Moroz K, Zhang H, Mulholland D, Abdel-Mageed AB, Mondal D: PRL3 increases the aggressive phenotype of prostate cancer cells in vitro and its expression correlates with high-grade prostate tumors in patients. Int J Oncol 2018, 52:402-412

42. van Poppel H, Haese A, Graefen M, de la Taille A, Irani J, de Reijke T, Remzi M, Marberger M: The relationship between prostate cancer gene 3 (PCA3) and prostate cancer significance. BJU Int 2012, 109:360-366

43. Wu Q, Hong J, Wang Z, Hu J, Chen R, Hu Z, Li B, Hu X, Zhang Z, Ruan Y: Abnormal ribosome biogenesis partly induced p53dependent aortic medial smooth muscle cell apoptosis and oxidative stress. Oxid Med Cell Longev 2019, 2019:7064319 